\title{
The Effects Of Adaptation, Commitment And Trust In Cross-Cultural Marketing Relationships
}

James R. Walton, University of Houston - Victoria Ronald J. Salazar, University of Houston - Victoria Jifu Wang, University of Houston - Victoria

\begin{abstract}
The spread of global business presents distinct challenges for those wishing to develop marketing relationships. Key elements of successful marketing relationships have been explored in the literature and are well understood (Morgan and Hunt, 1994; Walters, Peters, and Dess, 1994; Anderson and Narus, 1990). This paper expands the understanding of cross-cultural marketing relationships in three ways. It does so first by empirically testing a model of commitment and trust in an international context. Then the paper presents findings that suggest that cultural adaptation by the focal firm has a significant effect on commitment. We hypothesize that a firm's adaptation to its partner's culture significantly effects cooperation in cross-cultural marketing relationships and test the hypotheses by taking a structural equations approach. This paper finds that efforts made by the firm to adapt to the partner's culture improve relationship performance and that higher levels of Trust lead to higher levels of Commitment and that higher levels of both Trust and Commitment lead to greater Cooperation.
\end{abstract}

Keywords: International Strategy, International Marketing, Global Relationships, Cross-cultural partnerships, Empirical studies, Structural Equations

\section{INTRODUCTION}

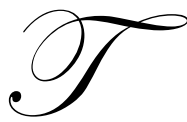

his research provides those interested in cross-cultural marketing relationships with a better understanding of the role of cultural adaptation. The focus of this study is on testing whether a firm's adaptation to its partner's culture significantly affects cooperation in cross-cultural marketing relationships. Responding to two emergent trends - increasing globalization and the need for developing successful marketing networks, this paper begins by testing Commitment - Trust theory in an international context. Then a conceptual model of the effects of cultural adaptation on commitment and trust in cross-cultural marketing relationships is presented, research hypotheses developed and tested and the results presented. Global marketing networks are seen as a key to prosperity in the future (Sin, Tse, Yau, Chow, and Lee 2005). Morgan and Hunt (1994, p. 20) for example maintain that, "to be an effective competitor (in the global economy) requires one to be an effective cooperator (in some network)." This is not easily accomplished. Sherman (1992) and others have observed that roughly one-third of international alliances have failed. One reason for this may be that most firms are "nearsighted" with "their field of vision dominated by home country" stakeholders and that everyone else "is simply part of "the rest of the world"" Ohmae (1990, p. 38). As the globalization of business increases, some marketing network components will naturally come under foreign control. To be successful, firms must deal with real and perceived cultural differences that sometimes dominate such relationships. Failure to understand the salient attitudes and behaviors when working with other cultures can lead to "millions of dollars in wasted negotiations, lost sales, and calamitous customer relations" (Sandhusen, 1997, p. 170). 


\section{THE ADAPTATION CHALLENGES OF CROSS-CULTURAL MARKETING RELATIONSHIPS}

Strategic marketing relationships are formed for many reasons. Among the purposes for which such relationships are the entering of new markets, reducing costs, moderating risk, or developing new technologies (Walters, Peters, and Dess 1994; Kalwani and Narayandas 1995, Rosa and Spanjol 2005). Bucklin and Sengupta (1993) found the effectiveness of a cooperative marketing relationship is affected by management of the alliance, payoff, and the level of match between partners. Morgan and Hunt's who employed trust and commitment as key mediating variables in relationship marketing argued that these factors encourage partners to persist in relationships. Cross-cultural marketing relationships obviously present unique challenges. For example, the "ability to compete globally may depend on how managers - and the organizations they comprise - view the world" (Kobrin (1994) p. 508).

To be successful in such uniques marketing relationships, managers must both understand and develop the skills necessary to deal with both the real and the perceived cultural differences that often dominate such relationships. Recall that according to Sandhusen the failure to understand the salient attitudes and behaviors toward working with other cultures can lead to "calamitous" results (1997, p. 170). Hunt and Morgan (1995) assert that "companies that think globally will enjoy significant competitive advantages over those that treat their foreign operations and divisions as subsidiary" to home nation operations (p. 20). Although perhaps more difficult to manage, cross-cultural relationships might actually be, at times, preferable to within-culture alliances. Austin (1990) maintains that "cultural differences can be an asset rather than a liability" and that "different perspectives and approaches," when combined to achieve synergy, can lead to superior performance (p. 356).

An important step in developing a successful cross-cultural marketing relationship is understanding how management ought to deal with inherent cultural differences (Johnson et al. 1996, p. 985. Although the importance of cultural sensitivity and adaptation in managing cross-cultural marketing relationships seems intuitive, it has not yet been widely examined in the literature. In their 1996 study of Japanese-U.S. International Cooperative Alliances, Johnson, Cullen, Sakano, and Takenouchi examined the role of cultural sensitivity, defined as "the extent to which managers understand and adapt to differences in their partner firm's culture" (p. 991), as an antecedent of trust in marketing relationships. They found that the partner firm's cultural adaptation was significantly related to the focal firm's trust in the relationship. According to Johnson et al. (1996), to successfully manage the cultural differences inherent in cross-cultural marketing relationships, the firm must both recognize and adapt to its partner's relevant business and social behaviors. Similarly, in a study of ethical sensitivity, Sparks and Hunt (1998) maintain that "recognizing an ethical issue" is a "necessary precursor" for making ethical decisions. Johnson et al. conceive of cultural sensitivity as including both the recognition of cultural differences and the firm's efforts to deal with them. Cultural adaptation then is defined here as the degree to which the firm accommodates cultural differences. The firm's ability to understand and adapt to other cultures (i.e., its cultural adaptation) can be a key factor of success in cross-cultural marketing relationships. Management's understanding of both the home firm's and the partner's efforts to adapt to each other's culture is considered essential to the development of successful cross-cultural relationships (Rosson, 1982).

\section{CONCEPTUAL DEVELOPMENT}

Morgan and Hunt explored the role of commitment and trust in Relationship Marketing (1994). Their results were persuasive in identifying two key mediating variables in a domestic context. At least two important extensions to their efforts are indicated. First, the literature suggests that such cultural adaptation is important for the development of commitment and trust in cross-cultural marketing relationships. Although shared values are often taken for granted and might be overlooked in domestic relationships, firms involved in a cross-cultural marketing relationship are not likely to hold common values with their partners. Thus, cultural adaptation by both the focal firm and its cross-cultural partner might be required to lead to trust and commitment in such relationships.

A conceptual model of the proposed extension of Morgan and Hunt's Commitment-Trust Theory of Relationship Marketing to cross-cultural marketing relationships is presented in Figure 1. The arrows in the model correspond to the predicted relationships of the hypotheses. All relationships depicted in the model are hypothesized to be positive except the relationship of Opportunistic Behavior to Trust. 


\section{Model of Cross-cultural Marketing Relationships}

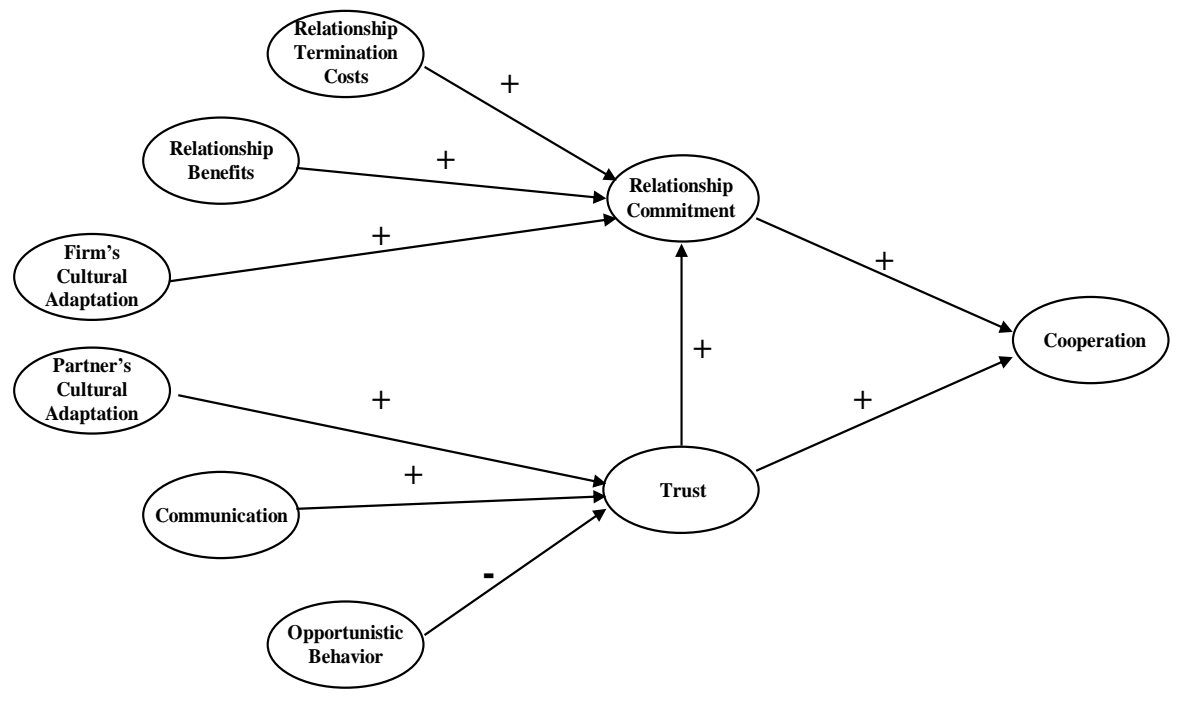

Figure 1: Model of Cross-cultural Marketing Relationships

Relationship termination costs (i.e., "switching costs") are assumed to lead to dependence in the relationship. Indeed, Morgan and Hunt (1994) found support for their hypothesis that relationship termination costs lead to commitment in the relationship and such a link is also hypothesized for cross-cultural marketing relationships.

Hypothesis 1: Relationship Termination Costs are positively related to Commitment in cross-cultural marketing relationships.

Although the hypothesized positive relationship of benefits to commitment was not found significant in Morgan and Hunt's study, they believe that this may have been due to measurement issues particular to the sample. They contend that the "level of benefits received from the relationship would be related strongly to both satisfaction with those benefits and satisfaction with the overall relationship.

Hypothesis 2: Relationship Benefits are positively related to Commitment in cross-cultural marketing relationships.

Johnson, Cullen, Sakano, and Takenouchi (1996) point out that dealing with and managing the cultural differences in a cross-cultural marketing alliance often entails a significant amount of effort and understanding on the part of management of both firms and that "a lack of cultural sensitivity can easily lead to misunderstandings in cross-cultural interfirm relationships" (p. 985). 
Recall that Morgan and Hunt (1994) warn that in cross-cultural relationships "one factor that can make an alliance doubly difficult is a potential lack of shared values." Although the results of a 1996 study by Johnson, Cullen, Sakano, and Takenouchi found no support for the hypothesis that "greater similarity between the focal firm and its partner results in higher levels of focal firm trust of its partner," Morgan and Hunt (1994) found that shared values, defined as "the extent to which partners have beliefs in common about what behaviors, goals, and policies are important or unimportant, appropriate or inappropriate, and right or wrong" have a significant effect on relationship trust. Unless firms believe that their counterparts have similar values it is difficult for them to "have confidence in an exchange partner's reliability and integrity" (Morgan and Hunt, 1994, p. 23).

If the partners in the relationship have similar values the relationship is likely more viable and likely to exhibit higher levels of trust. However, since participants in cross-cultural marketing relationships assume that their partner's values are different from their own, cultural sensitivity on the part of both partners is considered necessary to overcome those differences. Purposeful action is required. As Hunt and Morgan (1995) state "successful alliances, like successful marriages, don't just happen" (p. 25). Successful cross-cultural alliances require not only the recognition of cultural differences but effort on the part of both parties to address differences. Although they did not explore the role of commitment in such relationships, Johnson et al. speculated that such "cultural understanding and adapting require a substantial investment" on the part of the firm that also indicates the firm's commitment to the relationship (p. 986).

Hypothesis 3: The Firm's cultural adaptation is positively related to Commitment in cross-cultural marketing relationships.

Johnson et al. concluded that "cultural sensitivity provides a foundation for trust development" in such relationships (p. 985). Following the findings of Johnson, et al. (1996), the Partner's Cultural Adaptation within a firm is hypothesized to relate positively to Trust.

Hypothesis 4: The Partner's Cultural Adaptation is positively related to Trust in cross-cultural marketing relationships.

Good communication, essential in any marketing relationship, is especially difficult in cross-cultural marketing relationships. "Defined broadly as the formal as well as informal sharing of meaningful and timely information between firms" (Anderson and Narus, 1990, p. 44), the elements of communication in cross-cultural marketing relationships include both the verbal and non-verbal aspects of language, as well as the willingness of relationship partners to work to resolve communication differences. Morgan and Hunt (1994) found support for the hypothesis that communication is an antecedent of trust in marketing relationships. Following Morgan and Hunt's findings, a positive relationship is expected between Communication and Trust.

Hypothesis 5: Communication is positively related to trust in cross-cultural marketing relationships.

A number of studies have shown that when a party in a relationship believes that its partner is behaving opportunistically, trust is affected (Williamson, 1975; John, 1984; Morgan and Hunt, 1994; Romar 2004). Johnson et al. (1996) also concluded that "the marriage of firms from different cultures creates a potential for opportunism, conflict, and mistrust” (p. 1000). Following Morgan and Hunt's findings, a negative relationship between Opportunistic Behavior and Trust is hypothesized.

Hypothesis 6: Opportunistic Behavior is negatively related to trust in cross-cultural marketing relationships.

Previous studies in marketing relationships (Morgan and Hunt, 1994; Anderson and Narus, 1990; Fraizer, Spekman, and O'Neal, 1988; Howard and Sheth, 1969), have found support for the hypothesis that trust is positively related to both commitment and cooperation in marketing relationships, and that commitment is positively related to cooperation.

Hypothesis 7: Trust is positively related to commitment in cross-cultural marketing relationships. 
Hypothesis 8: Trust is positively related to cooperation in cross-cultural marketing relationships.

Hypothesis 9: Commitment is positively related to cooperation in cross-cultural marketing relationships.

\section{METHODOLOGY}

In this study both the focal firm's cultural adaptation and their perception of their partner's cultural adaptation are incorporated into Morgan and Hunt's framework as antecedents to the key relational elements of commitment and trust in cross-cultural marketing relationships. The research design employed in this study was a cross-sectional, self-administered mail survey. Data were collected from a single key informant, usually the president or vice president for international operations, from one partner in the relationship. The data were assessed for both validity and reliability and then the hypotheses were tested using structural equation modeling using Linear Structural Relations (LISREL) software. Firms involved in a cross-cultural marketing relationship are not likely to share values. Therefore, cultural adaptation by both the focal firm and its cross-cultural partner is likely to lead to trust and commitment in such relationships.

A survey instrument was drafted using multiple item scales validated in previous studies along with appropriate demographic questions: (Morgan and Hunt, 1994; John, 1984; and Johnson et al 1996). Environmental factors commonly associated with doing business in different countries (legal, political, financial, economic, etc.) vary considerably in nature and intensity. To control for the variance in environmental factors the setting was restricted to responses from U.S. firms doing business with firms in Mexico. Mexico exhibits a strong propensity to buy goods from the United States and there are a great many firms doing business in that market since the advent of the North American Free Trade Agreement (NAFTA). Although Mexico exhibits a strong propensity to buy American goods and remains one of the best markets in the world for Americans, and in spite of its geographical proximity to the United States, Mexico is still considered by most observers to be "culturally distant" from the U.S. Many Mexicans still feel that "geography has made us close but tradition has made us more distant than ever".Condon, 1991, p. 80). However, despite our cultural differences, Mexico, with its propensity to buy American goods, remains one of the best markets in the world for Americans to seek new opportunities. And, with the largest economy in the world at their doorstep many Mexican firms seek successful long-term marketing relationships with their northern neighbors.

The Chambers of Commerce of Houston and Dallas, have membership listings identifying whether or not firms are involved in business abroad. These lists provided a good source of firms to include in this study.

Following the two stage method of data collection employed by Aulakh, Kotabe, and Sahay (1996), a total of 1,587 suitable firms were identified. Of those surveyed, 180 questionnaires were returned (11.34\%). Most respondent firms were privately held enterprises and represented an average of more than twenty-four years experience with international trade, conducting business in an average of 22 countries, and dealing with ten Mexican partners on average. Respondents had an average of eight years experience with the partner firm about which they answered the questionnaire, ranging from just 2 months to 35 years. While nearly twenty percent of firms in the sample had sales in excess on $\$ 100$ million, sales of the median respondent firm was less than $\$ 10$ million (USD).

Exploratory factor analysis was used for data screening of the measures associated with the constructs of interest. Factor loadings indicated that the Firm's Cultural Adaptation (FCA) was represented by two separate factors. Only one set of those items were included in further analysis. Following Anderson and Gerbing (1988) a two-step approach of using first a measurement model and then a structural equation model was employed. The measures were tested separately in a stepwise fashion prior to examining the full model. Overall, 20 items from the original survey instrument were deleted from the model in this process. The formative constructs and their single item indicates were the added to the model and tested. The model estimates are in Table one below 
Table One: Structural Model Estimates

\begin{tabular}{lcc}
\hline Path & Estimate & T-value \\
BENE $\square$ CMMT & 0.02 & 0.29 \\
TERM $\square$ CMMT & 0.24 & 2.51 \\
FCA $\square$ CMMT & 0.27 & 3.49 \\
PCA $\square$ TRST & 0.04 & 0.37 \\
COMM $\square$ TRST & 0.38 & 4.97 \\
OPPO $\square$ TRST & -0.27 & -3.16 \\
TRST $\square$ CMMT & 0.67 & 6.07 \\
TRST $\square$ COOP & 0.47 & 3.30 \\
CMMT $\square$ COOP & 0.38 & 3.33 \\
\hline
\end{tabular}

The resulting full measurement model produced a good fit GFI of 0.86 and an AGFI of 0.81 with a chisquare of 446.19 with 282 degrees of freedom. The RMSEA was .046 and the RMR was .055, Browne and Cudeck (1993). Next, a structural equations model was developed and tested. The analysis of this structural model resulted in a GFI of .85, an AGFI of .81, an RMR of .066, an RMSEA of .048, and a chi-square of 386.36 with 277 degrees of freedom.

Results of Hypothesis Testing

\begin{tabular}{|c|c|c|}
\hline $\mathrm{H} 1$ & $\begin{array}{l}\text { Relationship Termination Costs are positively related to Commitment in } \\
\text { cross-cultural marketing relationships. }\end{array}$ & Supported \\
\hline $\mathrm{H} 2$ & $\begin{array}{l}\text { Relationship Benefits are positively related to Commitment in cross-cultural } \\
\text { marketing relationships. }\end{array}$ & Not supported \\
\hline H3 & $\begin{array}{l}\text { The Firm's Cultural Adaptation is positively related to Commitment in } \\
\text { cross-cultural marketing relationships. }\end{array}$ & Supported \\
\hline $\mathrm{H} 4$ & $\begin{array}{l}\text { The Partner's Cultural Adaptation is positively related to Trust in cross- } \\
\text { cultural marketing relationships. }\end{array}$ & Not supported \\
\hline H5 & $\begin{array}{l}\text { Communication is positively related to trust in cross-cultural marketing } \\
\text { relationships. }\end{array}$ & Supported \\
\hline H6 & $\begin{array}{l}\text { Opportunistic Behavior is negatively related to trust in cross-cultural } \\
\text { marketing relationships. }\end{array}$ & Supported \\
\hline $\mathrm{H} 7$ & $\begin{array}{l}\text { Trust is positively related to commitment in cross-cultural marketing } \\
\text { relationships. }\end{array}$ & Supported \\
\hline $\mathrm{H} 8$ & $\begin{array}{l}\text { Trust is positively related to cooperation in cross-cultural marketing } \\
\text { relationships. }\end{array}$ & Supported \\
\hline H9 & $\begin{array}{l}\text { Commitment is positively related to cooperation in cross-cultural marketing } \\
\text { relationships. }\end{array}$ & Supported \\
\hline
\end{tabular}

In summary, the hypothesized model provided a good overall fit to the data. Seven (7) of the nine (9) research hypotheses were strongly supported, however, two (2) were found to be insignificant and therefore not supported.

\section{DISCUSSION AND CONCLUSIONS}

The hypothesized relationship of Relationship Termination Costs to Commitment (H1) was found to be significant in cross-cultural relationships as it had previously been in domestic studies. As in Morgan and Hunt (1994), the hypothesized relationship of Relationship Benefits to Commitment (H2) was not supported. This was might have been due to the lack of validity and reliability of the measures used. From a theoretical perspective, one of the main findings of this research that efforts made by the firm to adapt to the partner's culture improve relationship performance (H3). As proposed, the model supports the hypothesis that the Firm's Cultural Adaptation leads to greater Commitment in the relationship. 
We had also hypothesized that the Partner's Cultural Adaptation would lead to increased Trust in the relationship (H4), however, surprisingly, our findings do not support that hypothesis. One issue that may have bearing upon that lack of support is that this study only measured one side of the relationship dyad and the construct of the Partner's Cultural Adaptation was the respondent's perception of such. In their study of both sides of the relationship dyad Johnson et al. (1996) found that "trust was greater for the Japanese than for the U.S." firms involved in that study (p. 986). In addition, some literature on cultural adaptation contends that adaptive behaviors may actually lead to a lack of trust in the relationship because the observer believes that the actor is "faking it." In such cases the observer may perceive the actor's adaptive behavior as awkward or even gauche (Giles and Smith, 1979). Future research efforts might parse out these effects.

The hypothesized positive relationship of Communication to Trust (H5) and negative relationship of Opportunistic Behavior to Trust (H6) were found significant in this cross-cultural study as they had previously been in domestic studies. These findings verify that several of the elements of Morgan and Hunt's Commitment-Trust Theory of Relationship Marketing are supported in at least some cross-cultural, e.g. international, marketing relationships. Trust is positively related to both Commitment (H7) and to Cooperation (H8) in our results. As we thought, Commitment is positively related to Cooperation (H9) in cross-cultural marketing relationships.

This study expands the current understanding of cross-cultural marketing relationships by developing a model that incorporates and internationalizes existing models of relationship commitment and trust as key mediating variables in such relationships. Specifically, this study has generalized three of the previously identified antecedents of Trust and Commitment (Morgan and Hunt, 1994) in marketing relationships to the international arena and identified one new antecedent unique to cross-cultural marketing relationships (adaptation). Following previous research on domestic marketing relationships, this study also finds that higher levels of Trust lead to higher levels of Commitment in cross-cultural marketing relationships and that elevated levels of both Trust and Commitment lead to greater Cooperation in such relationships. The hypothesized relationship of Relationship Termination Costs to Commitment was found to be significant in cross-cultural relationships as it had been in domestic studies.

\section{MANAGERIAL IMPLICATIONS}

In today's international marketing relationships, managers must understand and develop the skills necessary to deal with both real and perceived cultural differences. The results of this study suggest several implications for managers of cross-cultural marketing relationships.

First, managers of cross-cultural marketing relationships can conclude that the costs of training executives in cross-cultural relations can indeed be worthwhile in establishing the types of long-term marketing relationships that lead to cooperation and increased profits for both partners.

Cultural training can help firms develop the cultural adaptation skills needed when dealing with foreign partners. Simple changes, such as not including lawyers in initial negotiations because foreign executives may consider their presence a lack of trust; or paying more attention when presented with a foreign executive's business card, can make a significant difference in the long-term outcome of the relationship between the two firms. This study has demonstrated that values need not be equal between partners for the relationship to succeed.

\section{LIMITATIONS}

To control for the variance of environmental factors commonly associated with doing business in different countries, the empirical setting of this study was purposely restricted to solicit responses from U.S. firms doing business with firms in only one country, Mexico. Although this is consistent with the interactive approach to internationalization of the Uppsala model (Johanson and Vahlne, 1990), it begs the question as to whether the findings of this study can be generalized to different contexts. The effects of cultural adaptation may vary depending upon whether or not the partner is located in a country that is considered developed, such as Japan, or a less developed country (LDC) such as Nigeria. Clearly in a country such as Mexico, which is considered quite culturally different from the United States, firms cannot do business the same as they would in the U.S. 
The second limitation is that the hypotheses were tested using only U.S. firms and only one side of the relationship dyad. Because only U.S. firms were surveyed, it is not possible to say that whether these findings can be generalized to other cultures (for example Japanese firms doing business in Mexico). It is possible that American managers' perceptions of the difficulties of doing business in Mexico differ from those of their Japanese counterparts as well as those of other cultures. This study only gathered data from one side of the relationship. An important aspect of international research must include examining the effects of cultural adaptation from the point of view of the foreign partner firm as well. In addition, including both sides of the dyad would have provided multiple informants for each relationship, thereby increasing validity.

\section{FUTURE DIRECTIONS}

In recent years we have seen a growing amount of research about the internationalization of marketing relationships has appeared. While certain elements of existing models of marketing relationships such as Morgan and Hunts' KMV Model of Relationship Marketing may be generalized to cross-cultural marketing relationships on a limited basis, other elements may not be. In light of the importance of global alliances to the success of business in the future, other elements of relationship models should be examined from a cross-cultural perspective as well.

Future studies of international marketing relationships might explore whether functional conflict in crosscultural relationships is also significant and how firms handle functional conflict in such relationships. This study, like many others of this nature, only studied one side of the relationship dyad. Sampling techniques as well as cultural and language problems often make studying both sides of a cross-cultural relationship dyad both difficult and prohibitively expensive. However, with increased globalization such studies may be reasonable and would contribute greatly to an increased understanding of cross-cultural marketing relationships.

\section{BIBLIOGRAPHY}

1. Anderson, James C. and James A. Narus (1990), A Model of Distributor Firm and Manufacturer Firm Working Partnerships, Journal of Marketing, Vol. 54 No. 1 (January), p. 42-58.

2. Aulakh, Preet S., Masaaki Kotabe and Arvind Sahay (1996), Trust and Performance in Cross-Border Marketing Relationships: A Behavioral Approach, Journal of International Business Studies, Special Issue, p. 1005-1032.

3. Freidman, Thomas L., (2005), The World is Flat: a brief history of the twenty first century, New York : Farrar, Straus and Giroux, 2005.

4. Herche, Joel (1994), Ethnocentric tendencies, marketing strategy and import purchase behavior, International Marketing Review, Vol. 11 No. 3, p. 4-16.

5. Howard, John A., and Jadish N. Sheth, (1969), The Theory of Buyer Behavior, New York, NY: Wiley

6. Hunt, Shelby D. (1991), Modern Marketing Theory: Critical Issues in the Philosophy of Marketing Science, Cincinnati:South-Western Publishing.

7. Hunt, Shelby D. and John R. Nevin (1974), Power in a Channel of Distribution: Sources and Consequences, Journal of Marketing Research, Vol. 11 (May), p. 186-193.

8. Hunt, Shelby D. and Robert M. Morgan (1995), Relationship Marketing in the Era of Network Competition, Marketing Management, Vol. 3 No. 1, p. 19-28.

9. Hunt, Shelby D., Richard D. Sparkman, and James B. Wilcox (1982), The Pretest in Survey Research: Issues and Preliminary Findings, Journal of Marketing Research, Vol. XIX (May), p. 269-273.

10. Hunt, Shelby D.; Wood, Van R.; Chonko, Lawrence B. (1989), Corporate Ethical Values And Organizational Commitment in Marketing, Journal of Marketing, Vol. 53, Issue 3, p. 79-91.

11. Johnson, Jean L., John B. Cullen, Tomoaki Sakano, and Hideyuki Takenouchi, 1996, Setting the stage for trust and strategic integration in Japanese-US cooperative alliances, Journal of International Business Studies, Vol. 27 (Special Issue Supplement), p. 981-1004.

12. Kalwani, Manohar U. and Narakesari Narayandas (1995), Long-term manufacturer-supplier relationships: Do they pay off for supplier firms?, Journal of Marketing, Vol. 59 No. 1, p. 1-16.

13. Kobrin, Stephen J. (1994), Is There a Relationship between a Geocentric Mind-Set and Multinational Strategy?, Journal of International Business Studies, Vol. 25, No. 3, p. 493-511. 
14. Levine, Robert A. and Donald T. Campbell (1972), Ethnocentrism: Theories of Conflict, Ethic Attitudes, and Group Behavior, New York:John Wiley \& Sons.

15. Levitt, Theodore (1986), The Marketing Imagination, New York: Free Press;Collier Macmillan.

16. Long, J. Scott (1983), Covariance Structure Models, An Introduction to LISREL, Beverly Hills, CA:Sage Publications.

17. Lusch, Robert (1976), Sources of Power: Their Impact on Intra-Channel Conflict, Journal of Marketing Research, Vol. 13 (August), p. 382-390.

18. Malnight, Thomas W. (1995), Globalization of an ethnocentric firm: An evolutionary perspective, Strategic Management Journal, Vol. 16 No. 2 (February), p. 119-141.

19. Moorman, Christine, Gerald Zaltman, and Rohit Deshpandé (1992), Relationships Between Providers and Users of Market Research: The Dynamics of Trust Within and Between Organizations, Journal of Marketing Research, Vol. 29 No. 3, p. 314-328.

20. Moran, Robert T. and William G. Stripp (1991), Dynamics of Successful International Business Negotiations, Houston: Gulf Publishing Company.

21. Morgan, Robert M. and Shelby D. Hunt (1994), The commitment-trust theory of relationship marketing, Journal of Marketing, Vol. 58 No. 3 (July), p. 20-38.

22. Morgan, Malcolm J. (1993), How Corporate Culture Drives Strategy, Long Range Planning, Vol. 26 , No. 2, p. 110-118.

23. Netemeyer, Richard G., Srinivas Durvasula, and Donald R. Lichtenstein (1991), A Cross-National Assessment of the Reliability and Validity of the CETSCALE, Journal of Marketing Research, Vol. 28 (August), p. 320-327.

24. Ohmae, K. (1990). The Borderless World--Power and Strategy in the Interlinked Economy. NY, NY: Harper and Row.

25. Pedhazur, Elazar J. and Liora Pedhazur Schmelkin (1991), Measurement, Design, and Analysis: An Integrated Approach, Hilldale, N.J.:Lawrence Erlbaum and Associates.

26. Perlmutter, Howard V. (1969), The Tortuous Evolution of the Multinational Corporation, Columbia Journal of World Business, January-February, p. 9-18.

27. Rhinesmith, Stephen H., John N. Williamson, David M. Ehlen, and Denise S. Maxwell (1989), Developing Leaders for the Global Enterprise, Training and Development Journal, Vol. 43 No. 4 (April), p. 25-34.

28. Rosa, J. A. and J. Spanjol 2005, Micro-Level Product-Market Dynamics: Shared Knowledge and Its Relationship to Market Development, Journal of the Academy of Marketing Science, Spring, Vol. 33 Issue 2, p197, 20p.

29. Rosson, Philip J.; Ford, I. David. Manufacturer-Overseas Distributor Relationships and Export Performance, Journal of International Business Studies, Fall82, Vol. 13 Issue 2, p57, 16p; (AN 4667742)

30. Romar, E. J., Globalization, Ethics, and Opportunism: A Confucian View of Business Relationships, Business Ethics Quarterly,2004 Oct, Vol. 14 Issue 4, p663, 16p.

31. Sandusen, R. L. International Marketing, Business Review Series, Barron's Educational Series, Inc. New York, 1997.

32. Satorra, A. and W.E. Sarris (1985), Power of the Likelihood Ratio Test in Covariance Structure Analysis, Psychometrika, Vol.50, p. 83-90.

33. Schein, Edgar (1990), Organizational Culture, American Psychologist, vol. 45, no. 2, February, p. $109-119$.

34. Sherman, Stratford (1992), Are Strategic Alliances Working?, Fortune, Vol. 126 No. 6 (Sept. 21), p. 77-78.

35. Thorelli, Hans B. and Aleksandra E. Glowacka (1995), Willingness of American Industrial Buyers to Source Internationally, Journal of Business Research, Vol. 32, No. 1 (January), p. 21-30.

36. Walters, Bruce A., Steve Peters, and Gregory G. Dess (1994), Strategic Alliances and Joint Ventures: Making Them Work, Business Horizons, Vol. 37 No. 4 (July/August), p. 5-10.

37. Williamson, O., Markets and Hierarchies, New York: Free Press, 1975. 
NOTES 